\title{
Fluid flow and heat transfer in an axially rotating pipe subjected to external convection
}

\author{
B. WEIGAND and $\mathrm{H}$. BEER \\ Institut für Technische Thermodynamik, Technische Hochschule Darmstadt, Germany
}

(Received 18 January 1991)

\begin{abstract}
The effects of external insulation and tube rotation on the heat transfer to a fluid flowing inside a tube are examined by analysis. The turbulent flow is assumed to be hydrodynamically fully developed. Heat transfer was found to be strongly suppressed by tube rotation. It is shown that the significance of external insulation on the Nusselt number increases with growing rotation rate of the pipe.
\end{abstract}

\section{INTRODUCTION}

FLuid flow and heat transfer in rotating pipes are not only of considerable theoretical interest, but also of great practical importance. An obvious technical application is a rotating power transmission shaft that is longitudinally bored and through which a fluid is pumped for cooling of turbine blades or for other purposes. The interactions between centrifugal forces and turbulence have been investigated experimentally and by analysis. In 1929, Levy [1] studied experimentally the flow in rotating pipes. Murakami and Kikuyama [2] measured the time-mean velocity components and hydraulic losses in an axially rotating pipe when a fully developed turbulent flow was introduced into the pipe. The pipe rotation was found to suppress the turbulence in the flow, and also to reduce the hydraulic loss. With increasing rotational speed the axial velocity distribution finally approaches the Hagen-Poiseuille flow. Kikuyama et al. [3] calculated the velocity distribution in the fully developed region of a rotating pipe with the help of a modified mixing length theory proposed by Bradshaw [4]. They assumed the tangential velocity to have a parabolic distribution $v_{\varphi} / v_{\varphi w}=(r / R)^{2}$ in the fully developed region, which was confirmed by experiments $[2,3]$. Reich and Beer [5] examined experimentally and by analysis the effect of tube rotation on the velocity distribution and the heat transfer to a fluid flowing inside a tube for fully developed turbulent flow conditions. They observed a remarkable decrease in heat transfer with increasing rotation rate, $N=R e_{\varphi} / R e_{D}$. For a hydrodynamic fully developed turbulent flow the thermal entrance region was examined by Weigand and Beer [6]. Their analytical investigation showed that the thermal entrance length increases remarkably with growing rotation rate. The theoretical findings were in good agreement with experiments. The theoretical analysis in ref. [6] was performed only for the boundary conditions of a constant heat flux and a constant temperature at the pipe wall. In most technical equipments, however, such bound- ary conditions will not prevail. In many cases the condition at the tube wall can be approximated more realistically with the help of a boundary condition of the third kind. In this case, constant wall heat flux and constant wall temperature represent limiting boundary conditions.

\section{ANALYSIS}

An analysis of the thermally developing turbulent flow, with fully developed velocity profile, is of great practical importance, because in most rotating machinery the geometric configurations are not long enough to guarantee fully developed flow conditions. By assuming an incompressible Newtonian fluid, with constant fluid properties, the equations of motion and the energy equation are uncoupled and can be solved separately. For the case of fully developed flow conditions, the momentum equations have been solved in ref. [5]. Figure 1 shows axial velocity profiles for two different flow-rate Reynolds numbers, with the rotation rate $N$ as parameter. The influence of tube rotation on the axial velocity profile is obvious. With increasing rotation rate $N$ the axial velocity profiles approach the parabolic shape of Hagen-Poiseuille flow, which corresponds to an increasing turbulence suppression due to pipe rotation. In Fig. 2 the distribution of the tangential velocity profile is depicted for two different flow-rate Reynolds numbers and different values of $N$. For hydrodynamically fully developed flow conditions no influence of the Reynolds number and of $N$ upon the shape of the tangential velocity profile can be observed. Therefore, the tangential velocity profile was approximated by

$$
\frac{v_{\varphi}}{v_{\varphi \mathrm{w}}}=\left(\frac{r}{R}\right)^{2}
$$

according to refs. [2,5]. For comparison, experimental results from ref. [5] are plotted in Figs. 1 and 2. Generally, the agreement between theory and experiments is found to be good.

Now, consideration is given to a fluid flowing inside 


\section{NOMENCLATURE}

$\begin{array}{ll}c_{n} & \text { specific heat at constant pressure } \\ D & \text { pipe diameter, } 2 R \\ k & \text { thermal conductivity } \\ l, l_{4} & \text { hydrodynamic and thermal mixing } \\ N & \text { length } \\ N u & \text { rotation rate, } R e_{\varphi p} / R e_{D} \\ N u & \text { Nusselt number } \\ P r & \text { Prandtl number } \\ \dot{q} & \text { heat flux density } \\ R & \text { inner pipe radius } \\ R_{\mathrm{a}} & \text { outer pipe radius } \\ r & \text { coordinate in radial direction } \\ R e_{D} & \text { flow-rate Reynolds number } \\ R e_{\varphi} & \text { rotational Reynolds number } \\ T & \text { temperature } \\ T_{\mathrm{a}} & \text { ambient temperature } \\ T_{\mathrm{b}} & \text { bulk temperature } \\ r & \text { velocity } \\ v_{\varphi w} & \text { tangential velocity at the pipe wall }\end{array}$
$\bar{v}_{z} \quad$ mean axial velocity over the pipe cross- section
$z \quad$ axial coordinate.

Greek symbols

$\begin{array}{ll}\alpha & \text { external heat transfer coefficient } \\ \Delta & \text { convective parameter } \\ \theta & \text { dimensionless temperature } \\ \lambda_{n} & \text { eigenvalues } \\ \rho & \text { density } \\ \chi & \text { overall heat transfer coefficient. }\end{array}$

Subscripts

$\begin{array}{ll}r & \text { radial } \\ w & \text { wall } \\ z & \text { axial } \\ 0 & \text { inlet } \\ \varphi & \text { tangential } \\ \infty & \text { fully developed. }\end{array}$

a circular tube from left to right, as shown in Fig. 3, with a fully established velocity profile. The pipe rotates about its axis with constant angular velocity $\omega$. For $z<0$ the fluid is considered to have a uniform temperature $T_{0}$. For $z \geqslant 0$, heat transfer takes place by conduction through the tube wall and by convection to the surroundings, which is maintained at a constant ambient temperature $T_{\mathrm{a}}$. Under the assumptions of negligible viscous dissipation as well as axial conduction in the fluid and in the tube wall and by considering the rotational symmetry of the problem, the energy equation takes the following form:

$$
\rho c_{p} v: \frac{\partial T}{\partial z}=-\frac{1}{r} \frac{\partial}{\partial r}\left(r \dot{q}_{r}\right)
$$

The radial component of the heat flux vector $\dot{q}_{\text {, }}$ can be modelled as a function of the time smoothed variables, with the help of a modified mixing length theory, according to [5]
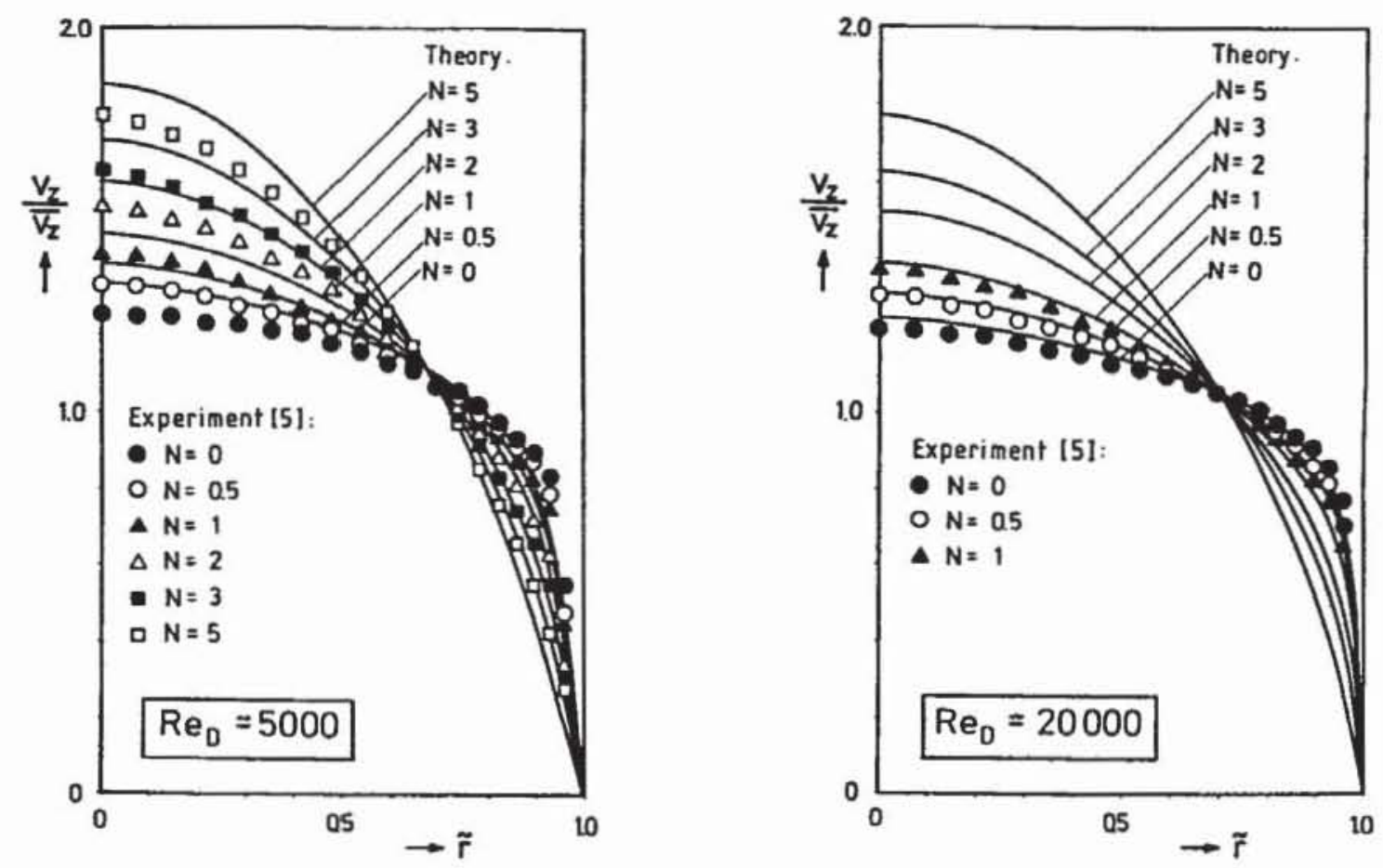

F1G. 1. Axial velocity distribution as a function of the rotation rate $N$. 

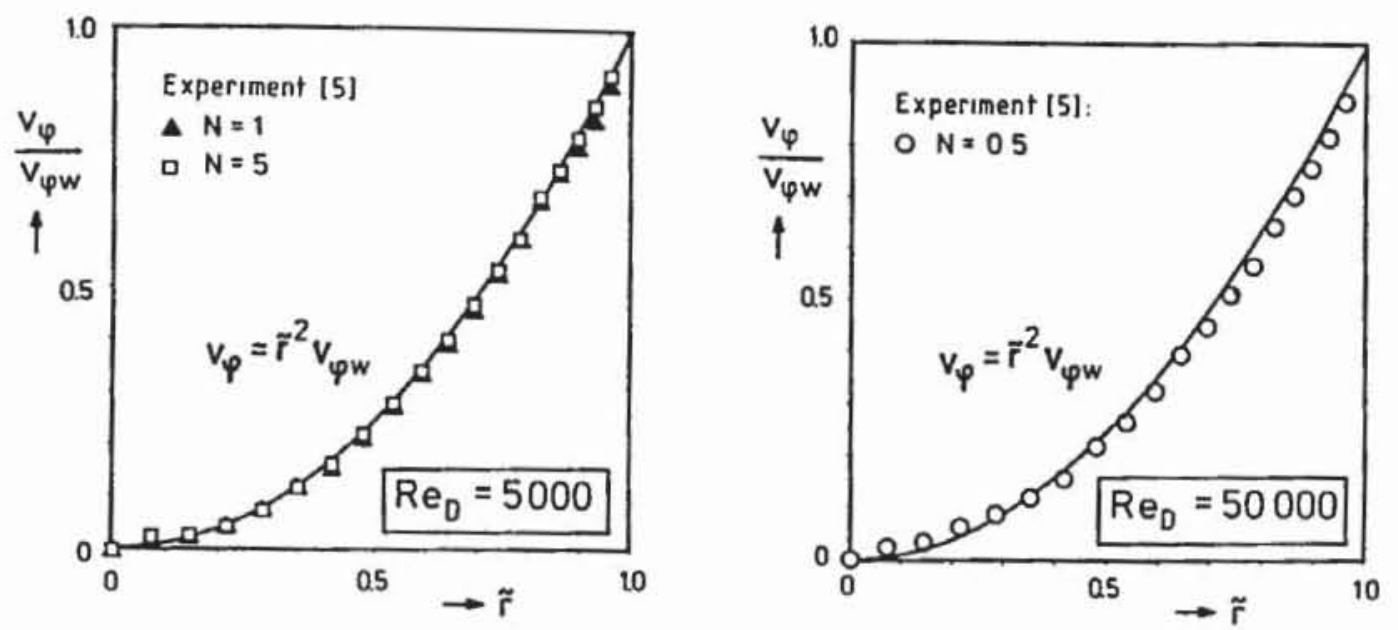

FIG. 2. Tangential velocity distribution as a function of the rotation rate $N$.

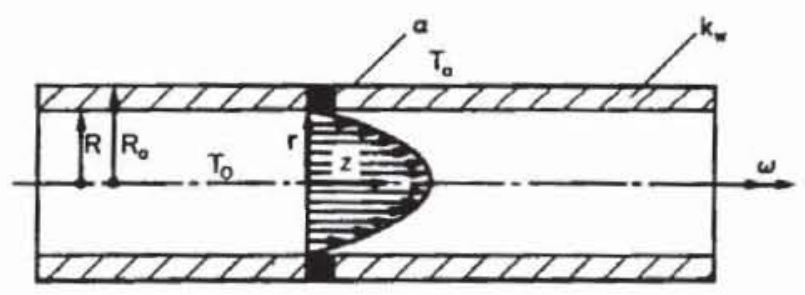

FIG. 3. Physical model and coordinate system.

$$
\begin{aligned}
\dot{q}_{r}=-k \frac{\partial T}{\partial r}-\rho c_{p} l_{\varphi}\left[\left(\frac{\partial v_{z}}{\partial r}\right)^{2}\right. & \\
& \left.+\left(r \frac{\hat{c}}{\hat{c} r}\left(\frac{v_{\varphi}}{r}\right)\right)^{2}\right]^{12} \frac{\partial T}{\hat{\partial} r} .
\end{aligned}
$$

The mixing lengths $l$ and $l_{4}$ are strongly influenced by tube rotation. For high values of the rotation rate $N$ the mixing lengths tend to zero and, therefore, heat transfer in the fluid is dominated by conduction, perpendicular to the flow direction. For further details the reader is referred to refs. $[5,6]$.

The boundary conditions belonging to the energy equation (2) are

$$
\begin{array}{ll}
z=0: & T=T_{0} \\
z>0, r=0: & \partial T / \partial r=0 \\
z>0, r=R: & -k(\partial T / \partial r)_{w}=\chi\left(T_{w}-T_{d}\right)
\end{array}
$$

where $\chi$ is the overall heat transfer coefficient

$$
\frac{1}{\chi}=\left[\frac{R}{\alpha R_{\mathrm{a}}}+\frac{R}{k_{\mathrm{w}}} \ln \left(\frac{R}{R_{\mathrm{a}}}\right)\right] .
$$

By introducing the following quantities:

$$
\begin{aligned}
& 0=\frac{T-T_{4}}{T_{0}}, \quad z=\frac{z}{D} \frac{4}{R e_{D} P r}, \\
& \tilde{r}=\frac{r}{R}, \quad \tilde{v}_{z}=\frac{v_{z}}{\bar{v}_{z}}, \quad N=\frac{R e_{\varphi}}{R e_{D}}, \\
& R e_{D}=\frac{\bar{v}_{z} D}{v}, \quad R e_{\varphi}=\frac{v_{\text {○े }} D}{v},
\end{aligned}
$$

$$
\operatorname{Pr}=\frac{y}{a}, \quad \Delta=\frac{\chi R}{k}
$$

the energy equation (2) is obtained in dimensionless form

$$
\tilde{i}_{z}(\tilde{r}) \tilde{r} \frac{\partial \theta}{\partial \bar{z}}=\frac{\hat{c}}{\partial \dot{r}}\left[E(\tilde{r}) \tilde{r} \frac{\partial \theta}{\partial \tilde{r}}\right]
$$

with the boundary conditions

$$
\begin{array}{ll}
z=0: & \theta=1-T_{\mathrm{a}} / T_{0} \\
z>0, \tilde{r}=0: & \partial \theta / \partial \tilde{r}=0 \\
z>0, \tilde{r}=1: & -\partial \theta / \partial \tilde{r}=\Delta \theta
\end{array}
$$

and with $E(\tilde{r})$ defined by

$$
E(\tilde{r})=1+\frac{R e_{D} \operatorname{Pr}}{2} \frac{l}{R} \frac{I_{q}}{R}\left[\left(\frac{\partial \tilde{v}_{z}}{\partial \tilde{r}}\right)^{2}+(\tilde{r} N)^{2}\right]^{12} .
$$

Equation (7), with the boundary conditions according to equation (8), represents a certain kind of turbulent Graetz problem with finite wall resistance. In the special case of laminar flow heat transfer $(E(\vec{r})=1)$ the problem under consideration was treated extensively by Hsu [7]. The linear, parabolic differential equation (7) can be solved by separation of variables:

$$
0=Z(\tilde{z}) H(\tilde{r}) \text {. }
$$

After inserting equation (10) into equations (7) and (8), the following Sturm-Liouville system is obtained:

$$
\frac{\mathrm{d}}{\mathrm{d} \tilde{r}}\left[E(\tilde{r}) \dot{r} \frac{\mathrm{d} H_{n}}{\mathrm{~d} \tilde{r}}\right]+i_{n}^{2} \tilde{v}_{z}(\tilde{r}) \tilde{r} H_{n}=0
$$

with the boundary conditions

$$
\begin{array}{ll}
\tilde{r}=0: & \mathrm{d} H_{n} / \mathrm{d} \tilde{r}=0 \\
\tilde{r}=1: & \mathrm{d} H_{n} / \mathrm{d} \tilde{r}+\Delta H_{n}=0
\end{array}
$$

and an arbitrary normalizing condition

$$
\tilde{r}=0: \quad H_{n}=1 .
$$

The eigenvalues $i_{n}$, which appear in the characteristic 
Table 1. Eigenvalues and constants for various flow-rate Reynolds numbers and various values of the convective parameter $\Delta$

\begin{tabular}{|c|c|c|c|c|c|c|c|c|c|c|}
\hline$N$ & $i_{i}^{2}$ & $i \frac{2}{2}$ & $i_{3}^{2}$ & $i_{4}^{2}$ & $i_{5}^{2}$ & $B_{1} H_{1}(1)$ & $\mathrm{B}_{2} \mathrm{H}_{2}(1)$ & $B_{3} H_{3}(1)$ & $B_{4} H_{4}(1)$ & $B_{5} H_{5}(1)$ \\
\hline \multicolumn{11}{|c|}{$R e_{D}=10000, \quad \Delta=0.5$} \\
\hline 0.0 & 0.9689 & 281.415 & 806.803 & 1559.047 & 2550.369 & 0.9693 & 0.00699 & 0.00411 & 0.00292 & 0.00215 \\
\hline 1.0 & 0.9590 & 132.138 & 412.794 & 829.431 & 1379.472 & 0.9591 & 0.01125 & 0.00500 & 0.00329 & 0.00247 \\
\hline 2.0 & 0.9400 & 70.789 & 223.292 & 453.960 & 762.100 & 0.9400 & 0.01940 & 0.00780 & 0.00460 & 0.00320 \\
\hline 3.0 & 0.9160 & 44.030 & 138.343 & 281.900 & 474.496 & 0.9154 & 0.02980 & 0.01160 & 0.00670 & 0.00450 \\
\hline 5.0 & 0.8656 & 23.719 & 73.519 & 149.727 & 252.317 & 0.8636 & 0.05080 & 0.01990 & 0.01120 & 0.00740 \\
\hline 20.0 & 0.8085 & 14.033 & 43.341 & 88.676 & 150.030 & 0.8034 & 0.07709 & 0.02985 & 0.01636 & 0.01050 \\
\hline \multicolumn{11}{|c|}{$R e_{D}=10000, \Delta=2$} \\
\hline 0.0 & 3.548 & 286.917 & 816.173 & 1572.081 & 2566.170 & 0.8869 & 0.0238 & 0.0144 & 0.0105 & 0.0079 \\
\hline 1.0 & 3.414 & 136.270 & 418.566 & 837.145 & 1389.178 & 0.8525 & 0.0374 & 0.0172 & 0.0116 & 0.0088 \\
\hline 2.0 & 3.184 & 74.538 & 228.095 & 459.851 & 769.062 & 0.7927 & 0.0607 & 0.0259 & 0.0159 & 0.0113 \\
\hline 3.0 & 2.910 & 47.499 & 142.720 & 287.112 & 480.477 & 0.7212 & 0.0852 & 0.0369 & 0.0222 & 0.0154 \\
\hline 5.0 & 2.435 & 26.690 & 77.322 & 154.211 & 257.381 & 0.5949 & 0.1202 & 0.0562 & 0.0342 & 0.0236 \\
\hline 20.0 & 2.000 & 16.511 & 46.552 & 92.422 & 154.207 & 0.4770 & 0.1487 & 0.0746 & 0.0459 & 0.0315 \\
\hline \multicolumn{11}{|c|}{$R e_{D}=10000, \Delta=10$} \\
\hline & 12.181 & 306.878 & 851.879 & 1624.395 & 2632.543 & 0.6056 & 0.0590 & 0.0394 & 0.0315 & 0.0256 \\
\hline 1.0 & 10.666 & 150.623 & 439.642 & 866.367 & 1427.242 & 0.5255 & 0.0829 & 0.0435 & 0.0315 & 0.0256 \\
\hline 2.0 & 8.588 & 86.163 & 244.354 & 480.842 & 794.849 & 0.4153 & 0.1060 & 0.0562 & 0.0385 & 0.0295 \\
\hline 3.0 & 6.755 & 56.715 & 155.959 & 304.107 & 501.040 & 0.3194 & 0.1118 & 0.0647 & 0.0453 & 0.0350 \\
\hline 5.0 & 4.548 & 32.582 & 86.456 & 166.306 & 272.206 & 0.2070 & 0.1000 & 0.0661 & 0.0497 & 0.0397 \\
\hline 20.0 & 3.169 & 20.271 & 52.756 & 100.902 & 164.725 & 0.1377 & 0.0843 & 0.0622 & 0.0493 & 0.0406 \\
\hline \multicolumn{11}{|c|}{$R e_{D}=50000, \quad \Delta=0.5$} \\
\hline 0.0 & 0.991 & 1117.011 & 3284.826 & 6432.384 & 10546.700 & 0.9906 & 0.00168 & 0.00088 & 0.00064 & 0.00053 \\
\hline 1.0 & 0.986 & 437.770 & 1398.714 & 2848.490 & 4778.357 & 0.9867 & 0.00332 & 0.00131 & 0.00080 & 0.00059 \\
\hline 2.0 & 0.979 & 211.537 & 681.041 & 1397.246 & 2358.361 & 0.9788 & 0.00662 & 0.00243 & 0.00138 & 0.00094 \\
\hline 3.0 & 0.967 & I17.291 & 376.829 & 773.957 & 1308.093 & 0.9665 & 0.01170 & 0.00426 & 0.00236 & 0.00156 \\
\hline 5.0 & 0.925 & 45.497 & 144.312 & 295.804 & 499.818 & 0.9244 & 0.02850 & 0.01055 & 0.00583 & 0.00381 \\
\hline 20.0 & 0.809 & 14.094 & 43.515 & 89.020 & 150.602 & 0.8039 & 0.07680 & 0.02980 & 0.01630 & 0.01050 \\
\hline \multicolumn{11}{|c|}{$0000, \Delta=2$} \\
\hline 0.0 & 3.854 & 1122.503 & 3293.367 & 6444.581 & 10563.100 & 0.9635 & 0.00638 & 0.00339 & 0.00248 & 0.00203 \\
\hline 1.0 & 3.794 & 442.020 & 1404.074 & 2855.212 & 4786.690 & 0.9485 & 0.01250 & 0.00497 & 0.00307 & 0.00227 \\
\hline 2.0 & 3.681 & 215.595 & 685.856 & 1402.864 & 2364.821 & 0.9197 & 0.02423 & 0.00909 & 0.00520 & 0.00355 \\
\hline 3.0 & 3.510 & 121.217 & 381.450 & 779.248 & 1314.030 & 0.8760 & 0.04105 & 0.01552 & 0.00874 & 0.00583 \\
\hline 5.0 & 3.004 & 49.004 & 148.534 & 300.642 & 505.208 & 0.7447 & 0.08547 & 0.03492 & 0.02000 & 0.01340 \\
\hline 20.0 & 2.004 & 16.575 & 46.730 & 92.772 & 154.786 & 0.4781 & 0.14840 & 0.07449 & 0.04580 & 0.03150 \\
\hline \multicolumn{11}{|c|}{$R e_{D}=50000, \quad \Delta=10$} \\
\hline 0.0 & 16.807 & 1148.075 & 3333.593 & 6502.517 & 10641.526 & 0.8399 & 0.02485 & 0.01359 & 0.01010 & 0.00842 \\
\hline 1.0 & 15.710 & 461.414 & 1428.891 & 2886.567 & 4825.780 & 0.7836 & 0.04603 & 0.01927 & 0.01213 & 0.00909 \\
\hline 2.0 & 13.866 & 233.126 & 707.335 & 1428.298 & 2394.357 & 0.6876 & 0.07837 & 0.03258 & 0.01937 & 0.01353 \\
\hline 3.0 & 11.621 & 136.676 & 400.760 & 801.985 & 1340.011 & 0.5696 & 0.10825 & 0.04868 & 0.02940 & 0.02044 \\
\hline 5.0 & 7.282 & 59.169 & 162.531 & 317.857 & 525.288 & 0.3432 & 0.12560 & 0.07042 & 0.04714 & 0.03468 \\
\hline 20.0 & 3.179 & 20.346 & 52.982 & 101.276 & 165.334 & 0.1382 & 0.08433 & 0.06211 & 0.04926 & 0.04059 \\
\hline
\end{tabular}

equation (11), can be calculated numerically by applying the Runge-Kutta method in the following manner: an eigenvalue is assumed and the solution of equation (11) is obtained numerically, according to the symmetry condition at the pipe centre and the normalizing condition (13). After that, the eigenvalue is varied until the boundary condition at the pipe wall is satisfied within a prescribed error bound, given by

$$
\tilde{r}=1:\left|\frac{-\mathrm{d} H_{n} / \mathrm{d} \tilde{r}}{\Delta H_{n}}-1\right|<10^{-4} \text {. }
$$

The calculated eigenvalues $\lambda_{n}$, as well as the constants $B_{n} H_{n}(1)$, are listed in Table 1 for various values of $\operatorname{Re}_{D}, N$ and the convective parameter $\Delta$.

After obtaining the eigenvalues of equation (11), the temperature distribution within the fluid is known:

$$
0(\tilde{r}, \tilde{z})=\sum_{n=1}^{x} C_{n} H_{n}(\tilde{r}) \mathrm{e}^{-i_{n}^{2 z}} .
$$

The constants $C_{n}$ have to be calculated in order to meet the required initial condition. After some manipulations one gets

$$
C_{n}=\left(1-\frac{T_{\mathrm{a}}}{T_{0}}\right) B_{n}=\left(1-\frac{T_{\mathrm{a}}}{T_{0}}\right) \frac{\Delta H_{n}(1)}{\lambda_{n}^{2} \int_{0}^{1} \tilde{v}_{z} \tilde{r} H_{n}^{2}(\tilde{r}) \mathrm{d} \dot{r}} .
$$

With the available temperature field one can proceed to derive the expression for the local Nusselt number, which is defined by

$$
N u=\frac{-D \partial T /\left.\partial r\right|_{\mathrm{w}}}{T_{\mathrm{w}}-T_{\mathrm{b}}} .
$$


From equation (15), the temperature gradient at the pipe wall is given by

$$
-\left.\frac{\partial T}{\partial r}\right|_{w}=\Delta \frac{T_{0}}{R} \sum_{n=1}^{x} C_{n} H_{n}(1) \mathrm{e}^{-\frac{i x}{n}} .
$$

Utilizing the definition of the bulk temperature, the temperature difference $T_{\mathrm{w}}-T_{\mathrm{b}}$, which appears in equation (16), can be expressed in the following form:

$$
\begin{aligned}
& T_{\mathrm{b}}=\frac{\int_{0}^{R} v_{z} r T \mathrm{~d} r}{\int_{0}^{R} v_{z} r \mathrm{~d} r}=2 \int_{0}^{1} \tilde{v}_{z} \tilde{r} T \mathrm{~d} \tilde{r} \\
& \frac{T_{\mathrm{w}}-T_{\mathrm{b}}}{T_{0}}=\left(1-\frac{T_{\mathrm{a}}}{T_{0}}\right)-2 \Delta \sum_{n=1}^{x} \frac{C_{n} H_{n}(1)}{\lambda_{n}^{2}}\left(1-\mathrm{e}^{-\frac{\lambda \hat{n}^{2}}{2}}\right) \\
& -\sum_{n=1}^{\infty} C_{n} H_{n}(1) \mathrm{e}^{-\frac{2}{n} n^{2}} \text {. }
\end{aligned}
$$

After inserting equations (18) and (20) into equation (16), the local Nusselt number is found to be

$$
\begin{aligned}
& N u=\left(2 \Delta \sum_{n=1}^{\infty} B_{n} H_{n}(1) \mathrm{e}^{-i_{n}^{2}}\right) \\
& \div\left(1-2 \Delta \sum_{n=1}^{x} \frac{B_{n} H_{n}(1)}{i_{n}^{2}}\left(1-\mathrm{e}^{-i_{n}^{2} z}\right)\right. \\
& \left.-\sum_{n=1}^{x} B_{n} H_{n}(1) \mathrm{e}^{-i_{n}^{2}}\right) \text {. }
\end{aligned}
$$

\section{RESULTS AND DISCUSSION}

The following results were obtained for air as the working fluid with $\mathrm{Pr}=0.71$. In Fig. 4 the Nusselt number for fully developed flow is plotted as a function of the flow-rate Reynolds number with the rotation rate $N$ as parameter. The variation of the Nusselt number with $R e_{D}$ for constant heat flux at the

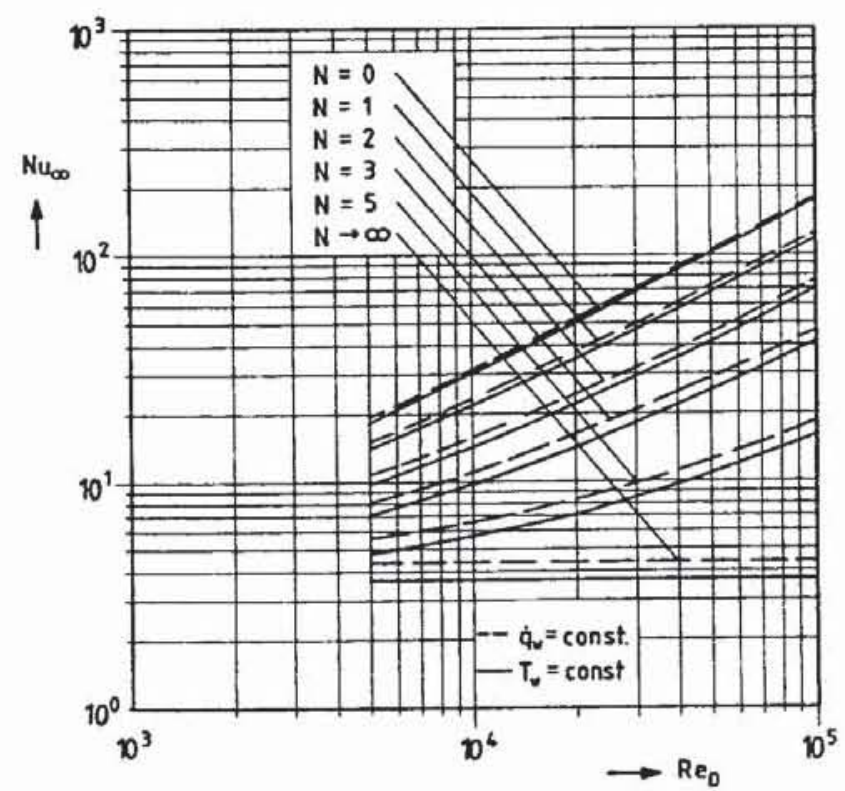

FIG. 4. Nusselt number $N u_{\infty}$ for fully developed turbulent flow. wall as well as for constant wall temperature is shown for each discrete value of $N$. The illustration elucidates the effect of relaminarization due to pipe rotation. With an increase in the rotation rate $N$, a remarkable decrease in the Nusselt number can be observed. For $N \rightarrow \infty$, the Nusselt number gradually approaches the value for laminar pipe flow. The curves for the Nusselt number for constant wall heat flux and constant wall temperature give an upper and a lower limit for the distribution of the Nusselt number according to the boundary condition of the third kind (see also ref. [8]). For large values of the convective parameter $\Delta$ one obtains $\theta=0$ from equation (8), which corresponds to the case of uniform wall temperature. For low values of $\Delta$, equation (8) represents the case of a nearly adiabatic wall, which is a special case of a constant heat flux at the wall. For low values of the rotation rate $N$, there is no significant difference between the Nusselt number for constant heat flux at the wall and constant wall temperature. The relative difference is approximately $2 \%$ and can be neglected. With increasing $N$ the Nusselt number approaches the value for laminar pipe flow. For this special case, the relative difference between the Nusselt numbers,

$$
\Delta F=\frac{\left(N u,{ }^{\prime}\right)}{\dot{q}_{\mathrm{w}}=\text { const. }-{ }^{(N u,)} T_{\mathrm{w}}=\text { const. }},
$$

reaches its maximum of $16 \%$ and should, therefore, not be neglected. Table 2 shows the relative difference $\Delta F$ for different flow-rate Reynolds numbers and various values of $N$. It can be seen that $\Delta F$ increases with decreasing $R e_{D}$, which is due to the more pronounced laminarization of the flow for low values of $R e_{D}$.

Figure 5 shows the distribution of the local Nusselt number versus $z / D$ for $R e_{D}=10000$ and various values of $N$. Every diagram contains curves of the local Nusselt number for constant heat flux at the pipe wall, for constant wall temperature and for selected values of the convective parameter $\Delta$. It is obvious that the curves for low values of $\Delta$ nearly coincide with those of the uniform wall heat flux case. The plots elucidate the decrease in heat transfer with increasing $N$. The Nusselt number decreases at every axial position for growing values of the rotation rate. This is due to the strong laminarization of the flow with increasing $N$.

In Fig. 6, the local Nusselt number, scaled with

Table 2. Relative difference $\Delta F$ between Nusselt numbers for $\dot{q}_{w}=$ const. and for $T_{w}=$ const.

\begin{tabular}{cccc} 
& & \multicolumn{2}{c}{$\Delta F(\%)$} \\
\cline { 3 - 4 } & $R e_{D}=5000$ & $R e_{D}=50000$ & $R e_{D}=100000$ \\
\hline$N=0$ & 4.5 & 2.3 & 17 \\
$N=1$ & 7.1 & 5.3 & 4.8 \\
$N=2$ & 9.7 & 8.3 & 8.0 \\
$N=3$ & 11.7 & 10.5 & 10.0 \\
$N=5$ & 14.0 & 12.5 & 12.3 \\
$N \rightarrow \infty$ & 16.3 & 16.3 & 16.3 \\
\hline
\end{tabular}



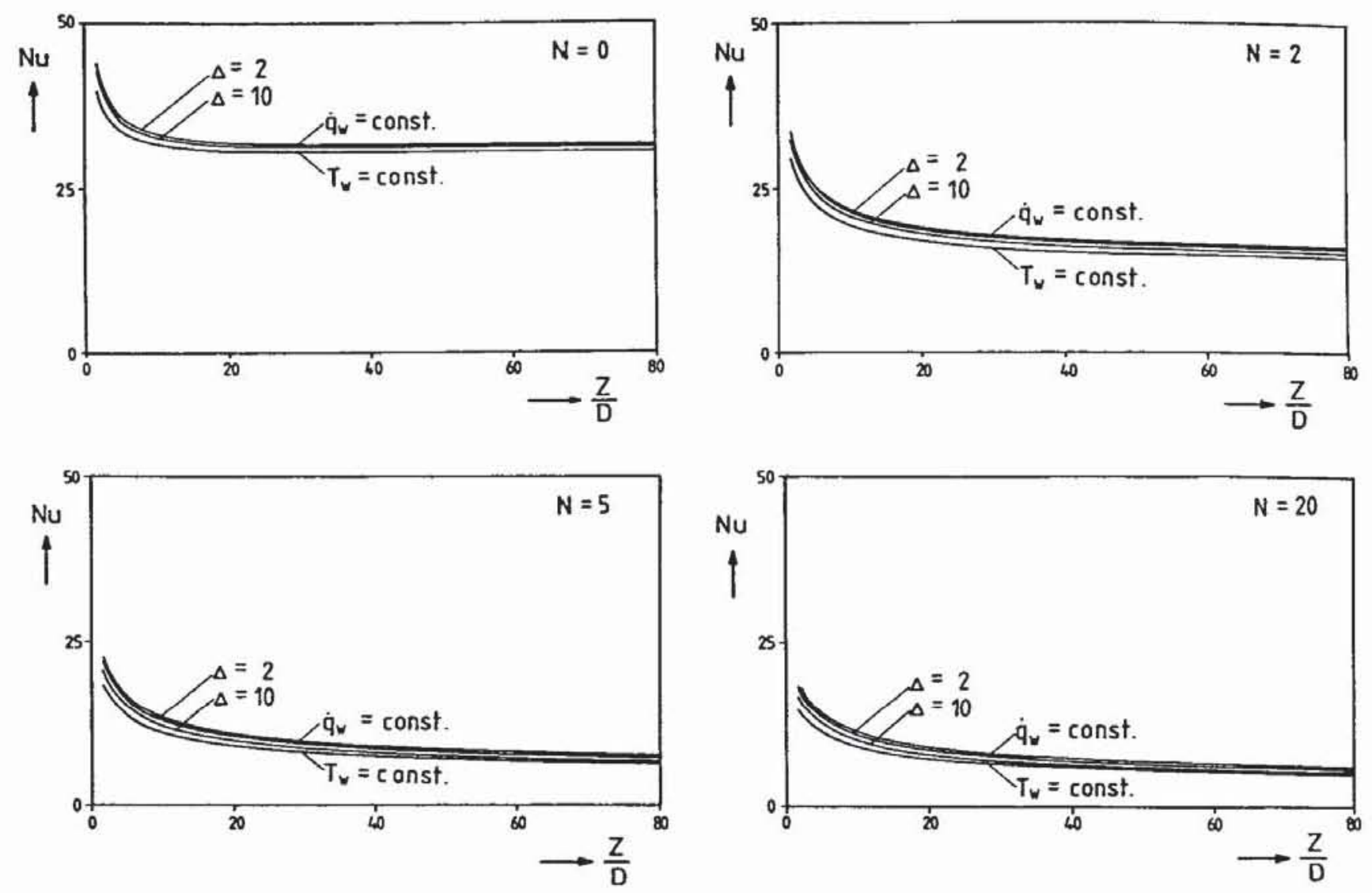

FiG. 5. Influence of the convective parameter $\Delta$ on the variation of the local Nusselt number $\left(R e_{n}=10000\right)$.

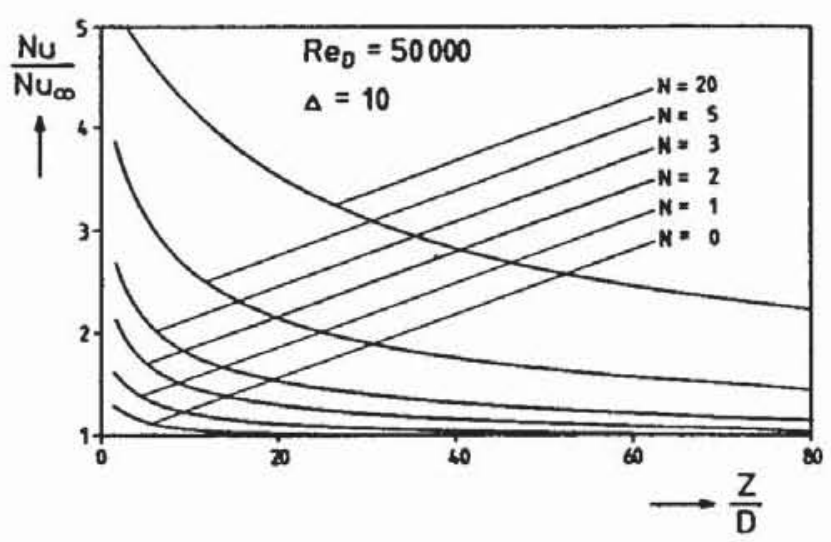

Fig. 6. Nusselt number as a function of $z / D$ with $N$ as parameter.

the Nusselt number for fully developed flow, $N u_{x}$, is plotted as a function of the axial coordinate for $R e_{D}=50000$ and $\Delta=10$, with $N$ as parameter. A remarkable increase in the thermal entrance length can be observed with increasing $N$. For $N \rightarrow \infty$, the thermal entrance length approaches that for a laminar pipe flow. which is given by $L / D=0.05 R e_{D} P r$. This means that the flow needs more than 200 pipe diameters to become thermally fully developed for $R e_{n}=50000 . P r=0.71$ and $N=3$, for example. This elucidates that the disregard of the laminarization phenomena in the thermal entrance region of an axially rotating pipe will underpredict heat transfer, which was also discussed in ref. [6].

\section{CONCLUSIONS}

From the preceding analysis the following major conclusions may be drawn.

1. The tube rotation causes a decrease in heat transfer due to the laminarization of the flow.

2 . With increasing rotation rate $N$, the thermal entrance region is markedly enlarged. This effect is nearly independent of the thermal boundary condition at the pipe wall.

3. In the case of a boundary condition of the third kind, it is commendable to consider the change in Nusselt number for low flow-rate Reynolds numbers and $N \geqslant 2$.

\section{REFERENCES}

1. F Levy, VDI Forschungsarbeiten auf dem Gebtet des Ingenieurwesens 32, 18 (1929).

2. M. Murakami and K. Kikuyama, J. Fluids Engng 102, 97 (1980).

3. K. Kikuyama, M. Murakami, K. Nishibori and K. Maeda, Bull. JSME 26, 506 (1983).

4. P. Bradshaw, J. Fluid Mech. 36, 177 (1969).

5. G. Reich and H. Beer, Int. J. Heat Mass Transfer 32, 551 (1989).

6. B. Weigand and H. Beer, Wärme- und Stoffübertragung 24, 191 (1989).

7. C. J. Hsu, J. Chin. Inst. Chem. Engng 2, 85 (1971).

8. R. K. Shah and A. L. London, Advances in Heat Transfer. Academic Press, New York (1978). 


\title{
ECOULEMENT FLUIDE ET TRANSFERT THERMIQUE DANS UN TUBE TOURNANT SUR SON AXE ET SOUMIS A UNE CONVECTION EXTERNE
}

Résumé-On analyse les effets de l'isolation externe et de la rotation d'un tube sur le transfert thermique à un fluide qui s'écoule à l'intérieur. L'écoulement turbulent est supposé être hydrodynamiquement établi. Le transfert de chaleur est fortement réduit par la rotation du tube. On montre que l'influence de l'isolation externe sur le nombre de Nusselt augmente avec l'accroissement de la vitesse de rotation du tube.

\section{DER EINFLUß DER ÄUBEREN ISOLATION AUF DIE WÄRMEÜBERTRAGUNG IN EINEM AXIAL ROTIERENDEN. DURCHSTRÖMTEN ROHR}

Zusammenfassung-Der Einfluß des àußeren Wärmeübergangs und der Rotation auf die Wärmeübertragung in einer turbulenten Rohrströmung im Bereich des thermischen Einlaufs wird theoretısch untersucht. Es wird angenommen, $\mathrm{da} \beta$ das Geschwindigkeitsprofil voll ausgebildet ist. Die Rotation hat aufgrund der radial ansteigenden Zentrifugalkräfte einen ausgeprägten Einfluß auf die Unterdrückung der turbulenten Bewegung. Dadurch verschlechtert sich die Wärmeübertragung mit steigender RotationsReynoldszahl. Weiterhin zeigt sich, daß der Einfluß der äußeren Isolation auf die Nusseltzahl mit steigender Rohrrotation zunimmt.

\section{ТЕЧЕНИЕ ЖИДКОСТИ И ТЕПЛОПЕРЕНОС В АКСИАЛЬНО ВРАЩАЮЩЕЙСЯ ТРУБЕ ПРИ НАЛИЧИИ ВНЕШНЕЙ КОНВЕКЦИИ}

\begin{abstract}
Amотяшя-Аналитически исследуется влияние внешней изоляции и вращения трубы на теплоперенос к потоку жидкости внутрн трубы. Предполагается, что поток является гидродинамически полностью развитым. Похазано, что вращение трубы значительно подавляет теплоперенос. Показано также, что с увеличением схорости вращения влияние внешней изолящия на число Нуссельта возрастает.
\end{abstract}

